\section{Contraceptive use dynamics research needs post fertility transition}

\author{
Siân L. Curtis*
}

Brazil, like many countries in the world today, has very low fertility and high contraceptive use. The TFR is now 1.8, below replacement level, and over $97 \%$ of sexually active women age 15-49 have used contraception at some time in their lives (BRASIL, 2008a). Despite the near universality of contraceptive use in Brazil today, $29.7 \%$ of births in the five years before the 2006 PNDS were reported as mistimed (wanted later) and $17.8 \%$ were reported as unwanted (BRASIL, 2008a). Similar patterns are observed in other low fertility, high contracepting populations; for example, in the United States $99 \%$ of women who have ever had sex have used contraception, yet one half of births in the US are unintended (MOSHER; JONES, 2010). In these contexts, a large proportion of unintended pregnancy is the result of contraceptive failure and inconsistent contraceptive use (BLANC; CURTIS; CROFT, 2002; BRADLEY; CROFT; RUTSTEIN, 2011). A large proportion of induced abortions are also preceded by contraceptive use in Brazil (BRASIL, 2008b).

Contraceptive discontinuation rates are high for most reversible methods. In Brazil in 1996, the most recent year for which data are available, 12 month discontinuation rates ranged from $42.3 \%$ among pill users to $62.8 \%$ among injectable users (BLANC; CURTIS; CROFT, 2002). In the same study, 12 month discontinuation rates for all reversible methods in Latin America ranged from $42.8 \%$ in Bolivia to $62.9 \%$ in the Dominican Republic, and in the United States, $46.3 \%$ of women who had ever used a contraceptive method reported having discontinued a method because they were dissatisfied with it (MOREAU; CLELAND; TRUSSELL, 2007). Side effects and health concerns are a major reason for discontinuing modern contraceptive methods; $11.8 \%$ of pill users and $27.4 \%$ of injectable users in Brazil in 1996 discontinued within 12 months due to side effects and health concerns, (LEITE; GUPTA, 2007) making them the largest single reason for discontinuing these methods. In the US, $64.6 \%$ of women who discontinued the pill and $72.3 \%$ of women who discontinued the injectable did so because of side effects (MOREAU; CLELAND; TRUSSELL, 2007). The picture is a little different for condoms; the main reasons for discontinuation of condoms relate to characteristics of the method such as inconvenience of use, dislike of the method by partners, interference with sexual pleasure, and concerns over the effectiveness of the method (MOREAU; CLELAND; TRUSSELL, 2007).

The strength of motivation to avoid pregnancy is another important factor. Analyses of the determinants of discontinuation consistently show demographic factors such as whether a woman is spacing or limiting births or her age to be more consistent determinants of discontinuation than socio-economic factors such as education or wealth status (CURTIS; BLANC, 1997; BRADLEY; SCHWANDT; KHAN, 2009). Women do not necessarily report births following discontinuation (for reasons other than desire to get pregnant) or failure as unintended (TRUSSELL, 1999; CURTIS; EVENS; SAMBISA, 2011) suggesting that ambivalence about pregnancy intentions plays a contributing role in discontinuation even when women do not explicitly state they are discontinuing contraceptive use in order to get pregnant. In the US, the National Survey of Family Growth has experimented with alternative methods of measuring fertility preferences and Santelli and colleagues have shown that

\footnotetext{
* Carolina Population Center and Dept. Maternal and Child Health, University of North Carolina at Chapel Hill, USA.
} 
these more nuanced measures that measure different dimensions of fertility preferences are strongly associated with the decision to abort a pregnancy (SANTELLI et al., 2009).

The contraceptive method used is also strongly and consistently associated with contraceptive discontinuation (CURTIS; BLANC, 1997; BRADLEY; SCHWANDT; KHAN, 2009). Methods such as IUDs and implants that require passive use and active discontinuation typically experience much lower discontinuation rates than methods such as pills, injectables and condoms that require active use and passive discontinuation. This means that countries that have relatively high levels of use of long acting and permanent methods, including sterilization, tend to have lower overall discontinuation rates than countries with lower levels of use of these methods in their method mix (BLANC; CURTIS; CROFT, 1999). Pills and condoms predominate in the mix of reversible methods used in Brazil tending to lead to high discontinuation rates among reversible methods. However, the high level of sterilization offsets this by eliminating the risk of discontinuation and failure once a woman decides to become sterilized.

Improved quality of family planning services such as improved information and counseling on side effects is often promoted to reduce contraception discontinuation and failure but the evidence on the effectiveness of such interventions in reducing contraceptive discontinuation is mixed (RAMARAO et al., 2003; FRONTIERS IN REPRODUCTIVE HEALTH, 2002; LEON et al., 2002). There is limited evidence on trends in discontinuation rates but the evidence that does exist suggests that discontinuation rates have generally declined over time in countries in Latin America, including in Northeast Brazil (BLANC; CURTIS; CROFT, 2002; BRADLEY; SCHWANDT; KHAN, 2009). The drivers of declines in contraceptive discontinuation are poorly understood and more work is needed to understand the relative importance of service environment factors, social networks, individual motivational factors, and method choice in these declines.
Exposure to the risk of unintended pregnancy increases as fertility preferences decline during fertility transition. According to the 2006 PNDS the unwanted TFR in Brazil is 0.2 births per woman (BRASIL, 2008a). The majority of women and couples are able to successfully limit their fertility, largely through the use of female sterilization, but one woman in five can expect to experience an unwanted birth during her reproductive life. The low fertility preferences now found in Brazil and in other low fertility populations require sustained use of effective contraception over the entire reproductive life course. Ambivalence about contraceptive use and about pregnancy intentions co-exist. Ultimately couples and individual women have to balance their ambivalence about contraceptive use and its side effects and their ambivalence about pregnancy in deciding whether to continue to use a contraceptive method. This balance no doubt varies over the life course and in response to external circumstances. In this context, understanding the dynamics of contraceptive use and what factors help women and couples to achieve sustained contraceptive use during different phases of their reproductive lives is critical. More nuanced measures of fertility preferences are also needed to better understand their role in contraceptive discontinuation and to better understand unintended pregnancy and its consequences in low fertility populations. Brazil, like many countries, lacks recent data on contraceptive discontinuation and failure and on the specific contraceptive behavior dynamics preceding unintended pregnancy. More data, both qualitative and quantitative, are needed on these issues. The 2006 PNDS provides new opportunities to examine the contraceptive behaviors of women who have experienced a recent unintended pregnancy which would add insights into this important topic even in the absence of specific data on discontinuation. The transition to near universal contraceptive use in Brazil raises an exciting new research agenda on the dynamics of contraceptive behavior over the reproductive life course. 


\section{References}

BLANC, A.; CURTIS, S.; CROFT, T. Monitoring contraceptive continuation: links to fertility outcomes and quality of care. Studies in Family Planning, v. 33, n. 2, p. 127-40, 2002.

BLANC. A.; CURTIS, S.; CROFT, T. Does contraceptive discontinuation matter? Quality of care and fertility consequences. Chapel Hill, NC: MEASURE Evaluation, Carolina Population Center and University of North Carolina, 1999.

BRADLEY, S. E. K.; CROFT, T. N.; RUTSTEIN, S. O. The impact of contraceptive failure on unintended births and induced abortion: estimates and strategies for reduction. Calverton, Maryland: ICF Macro, 2011 (DHS Analytical Studies, n. 22).

BRADLEY, S. E. K.; SCHWANDT, H. M.; KHAN, S. Levels, trends and reasons for contraceptive discontinuation. Calverton, Maryland: ICF Macro, 2009 (DHS Analytical Studies, n. 20).

BRASIL. Ministério da Saúde. Pesquisa Nacional de Demografia e Saúde da Mulher e da Criança - PNDS 2006. Relatório Final. Brasília/DF, 2008a.

Relatório "Aborto e Saúde Pública" - 20 anos de pesquisa no Brasil. Brasília, 2008. Available at: < http:// portal.saude.gov.br/portal/arquivos/pdf/ aborto_e_saude_publica_vs_preliminar. pdf>. Acessed: April 20, 2012.

CURTIS, S. L.; BLANC, A. K. Determinants of contraceptive failure, switching, and discontinuation: an analysis of DHS contraceptive histories. Calverton, Maryland: Macro International Inc., 1997 (DHS Analytical Reports, n. 6).

CURTIS, S.; EVENS, E.; SAMBISA, W. Contraceptive discontinuation and unintended pregnancy: am imperfect relationship. International Perspectives on Sexual and Reproductive Health, v. 37 , n. 2, p. 58-66, 2011.
FRONTIERS IN REPRODUCTIVE HEALTH. OR Summary 30: Services improve quality of care but fail to increase FP continuation. Washington, DC: Population Council, 2002.

LEON, F.; RIOS, Z.; ZUMARAN, A. Improving provider-client interactions at Peru $\mathrm{MOH}$ clinics: extent, benefit, cost. Final report. Washington, DC: Fronteirs in Reproductive Health, Population Council, 2002.

LEITE, I. C.; GUPTA, N. Assessing regional differences in contraceptive discontinuation, failure and switching in Brazil. Reproductive Health, v. 4, p. 6, 2007. Available at: <http://www.reproductivehealth-journal.com/content/4/1/6>. Accessed: April 22, 2012.

MOREAU, C.; CLELAND, K.; TRUSSELL, J. Contraceptive discontinuation attributed to method dissatisfaction in the United States. Contraception, n. 76, p. 267-272, 2007.

MOSHER, W. D.; JONES, J. Use of contraception in the United States: 19822008. National Center for Health Statistics. Vital Health Stat, v. 23, n. 10, 2010.

RAMARAO, S. et al. The link between quality of care and contraceptive use. International Family Planning Perspectives, v. 29, n. 2, p. 76-83, 2003.

SANTELLI, J. etal. Towards a multidimensional measure of pregnancy intentions: evidence from the United States. Studies in Family Planning, v. 40, n. 2, p. 87-100, June 2009.

TRUSSELL, J.; VAUGHAN, B.; STANFORD J. Are all contraceptive failures unintended pregnancies? Evidence from the 1995 national survey of family growth. Family Planning Perspectives, v. 31, n. 5, p. 246-7 \& 60, 1999. 